\title{
A EDUCAÇÃO FRONTEIRIÇA: MATRÍCULA, EVASÃO E REPROVAÇÃO DOS ALUNOS AYOREOS, NUMA ESCOLA DE PORTO MURTINHO/MS
}

\author{
Lucídia Balbuena Vareiro* \\ Daniela Sayuri Kawamoto Kanashiro**
}

RESUMO: O presente artigo apresenta uma análise de dados quantitativos de 2017, obtidos numa escola de Porto Murtinho, relativos a matrícula, evasão e reprovação de alunos ayoreos, cuja língua materna é o zamuco, em comparação aos índices de estudantes que têm como língua materna o português e dos que são falantes de espanhol e guarani. Os ayoreos são indígenas de nacionalidade brasileira e paraguaia, residentes na comunidade Punta, pertencente à colônia Carmelo Peralta, no Paraguai. Naquele ano, igualmente frequentaram a mesma escola considerada em nossa pesquisa, alunos brasileiros murtinhenses, além dos que possuíam nacionalidade brasileira e paraguaia, residentes em Carmelo Peralta, não indígenas, falantes de espanhol e guarani. Essa colônia paraguaia está separada do município brasileiro pelo rio Paraguai. Nosso trabalho justifica-se na medida em que existe carência de pesquisas sobre reprovação e evasão especificamente em escolas de fronteira. Conforme apontam Souza e Senna (2016), não temos políticas que reconheçam a pluralidade de situações de ensino e aprendizagem no país, o que pode contribuir para o processo de exclusão de alguns alunos. A fundamentação teórica se pauta em estudos sobre a fronteira, aspectos culturais, linguísticos e sobre a temática da evasão e reprovação. Os dados evidenciam que, conforme ocorre o avanço das séries/anos, há uma redução no número de matrículas dos ayoreos, o que demonstra que muitos deles não conseguem concluir o ensino fundamental. Dessa forma, verificamos que, embora seja assegurado o acesso à educação a esse grupo, não se garante a permanência de grande parte dos ayoreos no âmbito escolar.

\begin{abstract}
This article presents a quantitative data analysis from 2017 collected in a regular school in Porto Murtinho related to Ayoreo students' culture, school evasion and failures, of which their mother tongue is Zamuco, compared to students' index whose mother tongue is Portuguese and to the ones who are Spanish and Guarani speakers. The Ayoreos are indigenous with Brazilian and Paraguayan nationality, living in the Punta community in the Carmelo Peralta colony (Paraguay). In the referred year, the school considered in our research was also attended by Brazilian students from Porto Murtinho, beyond those who had Brazilian and Paraguayan nationality, resident in Carmelo Peralta, nonindigenous, Spanish and Guarani speakers. This Paraguayan colony is separated from the Brazilian city by the Paraguay river. Our research is concerned to the fact that there is a lack of researches about failure and school evasion, specifically in frontier institutions. According to Souza and Senna (2016), we do not have policies that recognize the plurality of teaching and learning situations in our country, which might contribute to the process of exclusion of some students. The theoretical grounding is based on studies about the border, cultural and linguistic aspects and about school evasion and failure issues. The data points out that, as the scholar levels/scholar years advance, there is an enrollment reduction with the Ayoreos, demonstrating that many of them cannot finish elementary and middle school. Thus, we have verified that, although the access to education is assured to this referred group, it is not guaranteed the permanence of a great part of the Ayoreos in the scholar scope.
\end{abstract}

PALAVRAS-CHAVE: fronteira; ensino fundamental; ayoreos.

KEYWORDS: border, elementary and middle school, Ayoreos.

DOI: $10.29327 / 214648.8 .31-1$ 


\section{INTRODUÇÃO}

Inquietações vivenciadas durante a docência, decorrentes de observações e também de conversas informais com outros colegas professores, levaram-nos a buscar mais estudos sobre questões educacionais a respeito das relações sociais e culturais dos alunos indígenas, não falantes de português, em escolas brasileiras. Nos anos de 2013 e 2014, em uma das escolas de Porto Murtinho, no estado de Mato Grosso do Sul (MS), localizada na zona rural, a cerca de seis quilômetros da zona urbana, aconteceu o primeiro contato com alunos que moravam no Paraguai, filhos de pais indígenas paraguaios, e que tinham nacionalidade paraguaia e brasileira ${ }^{\mathrm{i}}$, o que lhes garantiu a possibilidade de estudar no Brasil. Durante esses dois anos, estabelecemos contato com crianças indígenas que falavam o zamuco e que moravam na comunidade Punta, uma parte na colônia Carmelo Peralta, no Paraguai, e com outras, não indígenas, falantes de espanhol e guarani, mas também residentes no país vizinho. Elas atravessavam o rio Paraguai para terem acesso à educação básica, no município de Porto Murtinho. Ao chegarem à barranca, no lado brasileiro, deslocavam-se até ao ponto de ônibus para se dirigirem à escola.

Por meio desse contato diário, foi possível observar que esses estudantes, que vinham do Paraguai para frequentarem a escola brasileira, apresentavam dificuldades de aprendizagem principalmente na disciplina de Língua Portuguesa, já que a língua materna deles era o espanhol e o guarani e, no caso dos ayoreos, o zamuco. Também apresentavam dificuldades na interação com outras crianças e em sua inserção no ambiente escolar, sobretudo os indígenas. Esses estudantes ficavam isolados em sala de aula, e a comunicação se concretizava somente entre eles. Em 2017, os educandos, residentes no Paraguai, passaram a frequentar outro ambiente escolar e, por meio de uma parceria firmada entre a gestão local e o cacique da aldeia, instituiu-se uma lei municipali $^{\mathrm{ii}}$ para o transporte fluvial dos discentes moradores da colônia Carmelo Peralta, com objetivo de facilitar o traslado e o acesso à instituição de ensino mais próxima de suas residências, bem como diminuir os custos que os pais estavam tendo para trazerem seus filhos até Porto Murtinho. A parceria firmada com o gestor local sanou a dificuldade relacionada ao acesso escolar. No entanto, os problemas referentes à permanência dos ayoreos no contexto escolar, prosseguiram, conforme demonstram os dados das tabelas de 1 a 6 deste artigo.

Em síntese, a motivação para desenvolver a pesquisa nasceu das experiências docentes vivenciadas em 2013 e 2014, em contato com alunos indígenas paraguaios, os ayoreos. Em 2017, iniciamos a seleção do referencial teórico, consultando vários materiais como Barros (2017), que discute a fronteira entre Brasil e Paraguai; Bhabha (1998), que trata de aspectos culturais, além de Fornari (2010), Silva Filho e Lima Araújo (2017), por exemplo, que abordam estudos sobre reprovação e evasão. Na sequência, realizamos o levantamento do quantitativo de matrículas, evasão e reprovação de alunos

DOI: $10.29327 / 214648.8 .31-1$ 
brasileiros/paraguaios da comunidade indígena Punta, na colônia Carmelo Peralta, no Paraguai, falantes de zamuco (grupo 1), em comparação aos dados dos brasileiros residentes em Porto Murtinho, falantes de português (grupo 2) e dos brasileiros/paraguaios, também vindos de Carmelo Peralta, mas falantes de espanhol e guarani (grupo 3), conforme análise documental disponibilizado pela escola.

Neste estudo, procuramos identificar se os avanços das séries / dos anos levaram à redução no número de matrículas do grupo 1, comparando esses dados com os dos grupos 2 e 3, na escola Miranda ${ }^{\mathrm{iii}}$, indicando algumas hipóteses para compreender essas ocorrências, com base em nossa fundamentação teórica. Tencionamos, portanto, visualizar e compreender o fluxo escolar de alunos indígenas que residem no país vizinho e que estudaram na referida escola, em 2017. Consideramos que esses dados podem contribuir para: (i) discutir aspectos relacionados ao ensino e aprendizagem nas escolas de fronteira e nas instituições educacionais que recebem imigrantes; (ii) fomentar debates sobre como garantir a permanência e a aprendizagem de grupos considerados minoritários; (iii) intensificar e consolidar ações de acolhimento de alunos cuja língua materna não é o português; (iv) tratar da importância da formação do professor, inicial e continuada, no que diz respeito ao ensino de português como língua de acolhimento.

Para Souza e Senna (2016, p. 56), é preocupante "a ausência de pessoas que realmente estejam pensando sobre a política de inclusão para essa parcela ${ }^{\text {iv }}$ da sociedade, que tende a aumentar e não pode ser desprezada". Segundo os pesquisadores, faltam "políticas que reconheçam pluralidade em nosso país, fomentando o processo de exclusão" (SOUZA; SENNA, 2016, p. 55). Na sequência, o artigo apresenta fundamentação teórica, metodologia, análise dos dados coletados referentes a matrícula, evasão e reprovação de alunos, no ensino fundamental da escola Miranda, seguida de considerações finais e referências.

\section{FUNDAMENTAÇÃO TEÓRICA}

A primeira parte da fundamentação teórica objetiva compreender a concepção de fronteira e refletir sobre as línguas e a cultura nesse local. Também apresentamos os elementos que tornam o município de Porto Murtinho reconhecido como faixa fronteiriça. Na segunda parte, discutimos aspectos relacionados a evasão e reprovação à luz de estudos publicados por Fornari (2010), Silva Filho e Lima Araújo (2017), entre outros.

\subsection{FRONTEIRA, LÍNGUAS E CULTURA}

DOI: $10.29327 / 214648.8 .31-1$ 
De acordo com Barros (2017, p. 50), “muitas vezes 'fronteira' refere-se aos limites físicos e geográficos que delimitam, segregam e separam um território do 'outro'. Outras vezes, significa um espaço poroso e fluido, onde acontecem as trocas". Dessa forma, segundo a pesquisadora, a fronteira pode ser compreendida como um espaço que "junta e hibridiza" e também, contraditoriamente, como o que "afasta e exclui". Nesse sentido, Machado (1998, p. 41) assevera que:

\begin{abstract}
A origem histórica da palavra mostra que seu uso não estava associado a nenhum conceito legal e que não era um conceito essencialmente político ou intelectual. Nasceu como um fenômeno da vida social espontânea, indicando a margem do mundo habitado. Na medida em que os padrões de civilização foram se desenvolvendo acima do nível de subsistência, as fronteiras entre ecúmenos tornaram-se lugares de comunicação e, por conseguinte, adquiriram um caráter político.
\end{abstract}

Nessa concepção, é possível dizer que fronteira não representa um mero espaço que distancia dois países/povos distintos e, sim, um espaço de enunciações que se completam pela diversidade linguística-cultural existente, sendo um espaço/lugar de transformação e emancipação social, de costumes e política, que faz com que exista uma enorme diversidade entre os povos que ali habitam. Silva (2011, p. 63) afirma que "uma fronteira representa muito mais do que uma mera divisão e unificação dos pontos diversos. Vai além do limite geográfico. É um campo de diversidades. É o encontro com o 'diferente' físico e social. E é nesse espaço que as relações se formam e se deformam".

Nas faixas de fronteira entre o Brasil e o Paraguai, além das relações sociais, econômicas, culturais e políticas, temos também as interações com os povos indígenas, com diversas etnias que habitam esse território. Eles também contribuem para a formação da diversidade local. Dentro dessa complexidade, os povos indígenas são vistos apenas como os guardiões da fronteira, ou como agentes que necessitam de demarcações de suas terras nas regiões e que, frequentemente, são acusados de servir a interesses estrangeiros (PIMENTA, 2009). Entretanto, não se tem um olhar para a participação desses povos indígenas e sua contribuição na formação linguística e cultural na faixa fronteiriça, onde, muitas vezes, são excluídos e deixados de lado por não interagirem com a sociedade branca.

Nas regiões de fronteiras da América Latina, segundo CEPAL - Comissão Econômica para América Latina e o Caribe (2014), existem etnias indígenas que são de origem paraguaia como os: Ache, Angaié, Ava-guaraní, Ayoreo, Enxet norte, Enxetsur, Guaraníoccidental, Maká, Manjui, Maskoy, Mbya, Nivaclé, Ñandeva, Pai Tavytera, Sanapaná, Toba, Qom, Tomáraho e Ybytoso. Essas etnias compõem as comunidades que residem nas áreas fronteiriças, tendo sua contribuição para a formação da cultura,

DOI: $10.29327 / 214648.8 .31-1$ 
bem como da língua e dos dialetos locais. Compreender e reconhecer os povos que transitam e agregam os locais de cultura se torna primordial, pois segundo Bhabha $(1998$, p. 27) 'o trabalho fronteiriço da cultura exige um encontro com 'o novo' que não seja parte do continuum de passado e presente". Dito de outro modo, trata-se de algo que nos apresenta inovações e possibilidades que contribuem para a compreensão e a necessidade de romper com o passado, construindo o presente em um espaço cultural de comunicação, interação e aprendizagem.

A identidade de uma nação é o conjunto de traços que unifica um povo. Sua cultura se apresenta como conjunto de elementos simbólicos e materiais, estabelecendo uma continuidade histórica com seus ancestrais, seus heróis, sua língua, seus monumentos culturais, seu folclore, seus lugares e suas paisagens típicas; bem como, as representações oficiais, como hino, bandeira, escudo; identificações pitorescas, especialidades culinárias, animais e árvores-símbolo (THIESSE, 1999). Desse modo, a língua e a cultura de um povo são sua distinção frente a outras nações, sendo sua identidade. Assim, é importante compreender os fatores que influenciam sua permanência, evolução, transformação ou extinção. As línguas fronteiriças são fonte de riqueza e conhecimento, pois elas vão muito além da comunicação, representam histórias compartilhadas de um povo. Dessa forma, Fiorin (2013, p. 147) explica que "o que importa é a memória armazenada na língua, pois um idioma é a condensação da história de um povo, das influências que ele sofreu, dos seus desejos, de suas expectativas, de seus preconceitos, do modo de ser sua gente, de sua música, de sua literatura". Em outras palavras, a língua exerce um papel significativo na formação da identidade de um povo de determinada localidade ou de uma nação, principalmente, na região de fronteira, sendo um elemento de articulação com vários fatores que contribuem para seu valor social e identitário nacionalista. A região fronteiriça, em Mato Grosso do Sul, é um lugar de contatos linguísticos e culturais entre brasileiros, paraguaios e indígenas que, de certa forma, vão construindo suas identidades. Oliveira (2005, p.14) explana que:

\footnotetext{
É assim que em ambos os lados da fronteira pode-se constatar a existência de contingentes populacionais não necessariamente homogêneos, mas diferenciados pela presença de indivíduos ou grupos pertencentes a diferentes etnias, sejam elas autóctones ou indígenas, sejam provenientes de outros países pelo processo de imigração. Ora isso confere à população inserida no contexto de fronteira um grau de diversificação étnica que, somado à nacionalidade natural ou conquistada do conjunto populacional de um e de outro lado da fronteira, cria uma situação sociocultural extremamente complexa.
}

Conforme já mencionamos, os ayoreos transitam por essa faixa fronteiriça entre Paraguai e Brasil, uma vez que, embora residentes em outro país, muitas crianças estão matriculadas na rede de ensino público municipal brasileiro como alunos regulares. Contudo, grande parte delas têm o processo de ensino e aprendizagem comprometido, devido a vários fatores que interferem na aprendizagem, assim como na continuidade

DOI: $10.29327 / 214648.8 .31-1$ 
dos estudos. Desse modo, os indígenas do Brasil que passaram e ainda passam por grandes conflitos em busca de sua valorização cultural e identitária, a comunidade indígena ayoreo, residente na região fronteiriça Brasil/Paraguai, também possui uma trajetória histórica de lutas por pertencimento de suas tradições, identidade e língua. No decorrer dos anos, essa comunidade passou a ter contato e até mesmo a se apropriar de novos costumes dos locais por onde passavam, tornando-se uma forma de sobrevivência e defesa: "para poder seguir sendo é preciso deixar de ser muito do que era" (BARTOLOMÉ, 2000, p. 283). Muitos ayoreos mudaram seu modo de vida, bem como sua cultura sofreu interferências do mundo em constante transformação, mas conservam alguns valores. Ayoreos, assim chamados, possuem esse nome que significa "homens de verdade". É um termo cultural utilizado que expressa o modo de vida como caçadores e coletores. Estão divididos em sete clãs: Etaconi, Picanerai, Dosapei, Jnurumini, Chiquenoi, Cutamurajai e Posorajai. Cada clã possui uma marca com significado e reconhecimento específico. Esses clãs se encontram no território do Chaco, compreendido como uma região de cerrados e florestas densas que se ampliam do Paraguai a Bolívia e Argentina: "O povo Ayoreo é conhecido desde os primeiros tempos da conquista do Chaco. No século XVI são nomeados diferentes grupos que logo, no seguinte século, se associaram a etnia dos Zamuco; aqueles que posteriormente (na terceira década do século XX) se identificam como Ayoreo". (INICIATIVA AMOTOCODIE, 2016) ${ }^{\text {vi }}$. Os Ayoreos do Chaco Paraguaio trazem consigo um contexto de vida sofrida, de muitas batalhas enfrentadas e, muitas vezes, eram obrigados a saírem de suas terras em busca de oportunidades de sobrevivência e respeito. Em todos os territórios por que passaram, ficaram as marcas de suas vivências.

\begin{abstract}
Vão deixando sinais de sua existência diferenciada, como testemunho anônimo de sua luta contra a hegemonia imposta pelas nações modernas. Heranças espalhadas de um povo que foi submetido e reduzido caminham disseminando pelos bosques chaquenhos, configurando constelações irreconciliáveis com a febre da capital que domina o colonizador, para o neoamericano e, pouco a pouco, aos descendentes daqueles que foram originais da região. (INICIATIVA AMOTOCODIE, 2016) ${ }^{\mathrm{vii}}$.
\end{abstract}

A comunidade indígena Ayoreo com codinome "Punta", que também pertence ao Departamento do Alto Paraguai, está localizada na colônia Carmelo Peralta, a cerca de 300 metros de distância da margem do rio. Existem cerca de 968 indígenas Ayoreos nessa região, conforme dados divulgados pela Dirección General de Estadística, Encuentros y Censos (DGEEC) (PARAGUAY, 2012). Em relação à língua falada pelos ayoreos, trata-se do zamuco, conforme menciona Grünewald (2017). Para ter acesso ao local, é preciso utilizar canoas ou balsa que servem de meio de transporte fluvial para a locomoção dos paraguaios, indígenas e brasileiros. Conforme Franco (2015, p. 68):

No Paraguai, os Ayoreo foram contatados pelos missionários salesianos em 1962. Segundo a entrevista com o Pe. Carlos, da colônia Peralta, quando a igreja católica (salesianos) assume o serviço, como uma espécie de redução na época, mas que hoje não se usa mais o termo e (também não tem mais a

DOI: $10.29327 / 214648.8 .31-1$ 
presença da igreja nas comunidades), então, uma parte da população indígena começa a imigrar para a ação menonita em Filadélfia-PY e o outro grupo para a região do rio Paraguai, entre Carmelo Peralta e Porto Murtinho.

Diante dessa realidade, podemos observar que vários indivíduos da comunidade paraguaia indígena Ayoreo pertencem ao Departamento do Alto Paraguai, porém, ao atravessarem o rio, em direção ao lado brasileiro em busca de trabalho e de assistência à saúde e à educação, acabam usufruindo dos mesmos direitos dos brasileiros murtinhenses, o que torna essencial a existência de políticas públicas que contemplem esse grupo, sem que haja preconceitos e discriminações nos aspectos sociais, culturais e educacionais. A comunidade indígena ayoreo é composta por diversos líderes indígenas, ou seja, caciques, sendo que cada um representa uma família que veio de outras partes da região indígena ayoreo do Paraguai e que se instalou no local, vivendo como uma só comunidade, denominada "Punta". Essa comunidade pertence à colônia Carmelo Peralta. A comunidade indígena dos ayoreos tem como sustento a pesca, a caça, mas principalmente a venda de isca para o turismo pesqueiro brasileiro. Os ayoreos utilizam seus barcos a motores para fazerem a travessia de cargas e pessoas da cidade paraguaia de Carmelo Peralta para a cidade brasileira de Porto Murtinho. Os ayoreos desenvolvem também agricultura como o cultivo de mandioca, batata e hortaliças. Também é possível observar que, na comunidade, existem muitas crianças em idade escolar (referente à educação infantil). A grande maioria tem nacionalidade brasileira, além da paraguaia, mas ainda não foi matriculada em escolas de Porto Murtinho pela falta de conhecimento dos pais, no que diz respeito às leis educativas brasileiras. Destaca-se que, para muitos pais, o Brasil oferece melhor qualidade de ensino e maiores possibilidades de inserção social para seus filhos. Cabe evidenciar que alguns ayoreos, além de frequentarem a sala de aula no Brasil, também estudam no colégio de sua comunidade indígena. O conteúdo é transmitido na língua espanhola e zamuco e os materiais didáticos, como livros que vêm da capital Assunção, são escritos em espanhol.

Conhecer e compreender a cultura, a identidade e a língua dos educandos que estudam no Brasil, mas que moram no Paraguai, é de suma importância para a presente pesquisa, pois, por meio desse reconhecimento, é que podemos ter os elementos necessários para entender a vinda desses alunos ao Brasil em busca de educação e saúde, por exemplo.

\subsection{EVASÃO E REPROVAÇÃO ESCOLAR}

Se há anos a educação formal era restrita a uma pequena parcela da população, atualmente, ela é um direito de todos, conforme consta na Constituição Federal, de 1988, e na Lei de Diretrizes e Bases (LDB) N ${ }^{\circ}$ 9.394, de 1996. Contudo, o acesso à escola não implica permanência, aprendizagem. Vários alunos brasileiros não concluem a educação básica por motivos diversos. Auriglietti, 2014; Silva Filho; Lima Araújo, 2017, fundamentados em outros estudos, estabelecem ampla discussão sobre a diferença

DOI: $10.29327 / 214648.8 .31-1$ 
entre abandono e evasão escolar. O primeiro ocorre quando o aluno deixa a escola por um período, mas retorna posteriormente. Evasão corresponde à saída do aluno que não volta mais ao ambiente escolar. Em nossa pesquisa, analisamos apenas os dados coletados em 2017, referentes a matrícula, evasão e reprovação, na escola Miranda, de Porto Murtinho. Considerando que os resultados demonstram a diminuição no número de matrículas em séries mais avançadas, julgamos que a maior parte dos ayoreos, que deixaram de frequentar as aulas, não retornou em anos seguintes. Por isso, neste trabalho, utilizamos apenas o termo evasão.

Pesquisadores como Fornari (2010), Patto, 1999, Silva Filho e Lima Araújo (2017), por exemplo, desenvolveram estudos relacionados ao fracasso escolar, resultante de evasão e reprovação, problemas significativos constatados no ensino fundamental, no ensino médio e no ensino superior brasileiro. Há indicadores que mostram que é essencial e urgente compreender quais são as causas desse problema, a fim de saná-los ou de, ao menos, mitigá-los. Segundo Silva Filho e Lima Araújo (2017, p. 35),

\begin{abstract}
Fatores internos e externos, como drogas, tempo na escola, sucessivas reprovações, falta de incentivo da família e da escola, necessidade de trabalhar, excesso de conteúdo escolar, alcoolismo, localização da escola, vandalismo, falta de formação de valores e preparo para o mundo do trabalho, podem ser considerados decisivos no momento de ficar ou sair da escola, engrossando a fila do desemprego. [...]
\end{abstract}

Os fatores externos à escola estão concentrados no âmbito familiar, nas políticas de governo ou na própria criança (FORNARI, 2010). As tentativas, que procuram culpabilizar o aluno ou a família pelo fracasso escolar, tratam o problema como resultado de má-vontade, falta de esforço ou falta de orientação e acompanhamento familiar. Segundo Patto (1999), procura-se justificar a evasão e a reprovação indicando que o problema reside em fatores emocionais, orgânicos, neurológicos, em carência cultural e dificuldades de aprendizagem. Para Fornari (2010), se a desnutrição, ainda que moderada, pode ser uma das causas de alteração no desenvolvimento mental, se a necessidade de trabalhar acarreta a sobrecarga nas tarefas diárias do aluno, ambos fatores contribuem para reprovação e evasão. Temos, portanto, a culpabilidade centrada em questões individuais, justificada também pela pobreza. Isso tira a responsabilidade da escola. Esse tipo de pensamento "procura fazer com que as pessoas acreditem que o único responsável pelo sucesso ou fracasso social de cada um é o próprio indivíduo e não a organização social que o envolve" (FORNARI, 2010, p. 115).

No que se refere aos fatores internos à escola como causa da evasão e reprovação, ou seja, do problema não como condição individual, Shirassu e Arraes (2016, p. 4) citam, entre outros: "a baixa qualificação do professor, as práticas pedagógicas inadequadas para a realidade do aluno, a má qualidade do ensino, a falta de vagas [...]”. Aranha

DOI: $10.29327 / 214648.8 .31-1$ 
(2009 apud SILVA FILHO; LIMA ARAÚJO, 2017, p. 41), aponta que "os maiores dilemas enfrentados pelos jovens, na atualidade, no ensino médio, são turmas lotadas chegam a 50 alunos por sala, conteúdos extensos e específicos e professores despreparados para lidar com o estágio de desenvolvimento dos alunos". Para Silva Filho e Lima Araújo (2017, p. 41), a evasão e a repetência "São reflexos da forma como a escola recebe e exerce ação sobre as pessoas dos diferentes segmentos da sociedade". Quais são as condições de aprendizagem que a instituição oferece ao aluno?

De modo geral, costuma-se pensar e desenvolver os programas escolares como se todos os aprendizes tivessem os mesmos interesses, o mesmo arcabouço histórico e cultural, pressupondo um estudante ideal e famílias também ideais. Esses pesquisadores afirmam que "a utilização de um método didático superado ou de uma prática cristalizada como por inexperiência, acabam por desenvolver o conteúdo de forma descontextualizada e sem sentido para o aluno" (SILVA FILHO; LIMA ARAÚJO, 2017, p. 45). Sobre a prática do professor, é preciso considerar que a formação docente pode apresentar lacunas no que se refere, principalmente, à atuação em ambientes como os multiculturais. Os depoimentos expressos em estudo desenvolvido por Souza e Senna (2016, p. 63), indicam a "inexistência ou insuficiência de uma formação para as questões bilíngues da fronteira". Com base em Coracini (2007), os pesquisadores apontam

[...] a necessidade de uma formação específica para professores de escolas de fronteira, já que essas regiões são reconhecidas como laboratórios linguísticos naturais devido à sua formação étnico-linguística, resultante do fluxo migratório. Ela cita também a necessidade de se obter um material didático específico para as escolas de fronteira, que trate da realidade dessas regiões, um material que aborde a cultura e a história dos países fronteiriços, sem que haja uma visão nacionalista que gere preconceitos (SOUZA; SENNA, 2016, p. 64)

Dessa forma, compreendemos que os fatores que levam à evasão e à reprovação fazem parte de um complexo quadro. Aspectos sociais, políticos, culturais, cognitivos, históricos, linguísticos, afetivos devem ser levados em consideração no estudo de cada contexto. Em nosso caso, julgamos que ayoreos não podem se reduzir a índices de fracasso escolar, condenados a exclusão, invisibilidade e silenciamento.

\section{METODOLOGIA E ANÁLISE DOS DADOS}

Conforme mencionamos no início deste trabalho, a motivação para desenvolver a pesquisa nasceu das experiências docentes vivenciadas em 2013 e 2014, em contato com alunos ayoreos. Para o desenvolvimento do tema, foi utilizada a metodologia de abordagem qualitativa e quantitativa, com o emprego do estudo bibliográfico e documental. De acordo com Gil (2002, p. 44), “[...] a pesquisa bibliográfica é

DOI: $10.29327 / 214648.8 .31-1$ 
desenvolvida com base em material já elaborado, constituído principalmente de livros e artigos científicos", favorecendo o pesquisador com dados já elaborados, permitindo aprofundar-se nas teorias pertinentes ao tema. A pesquisa documental "vale-se de materiais que não recebem ainda um tratamento analítico, ou que ainda podem ser reelaborados de acordo com os objetos da pesquisa" (GIL, 2002, p. 45), oferecendo fontes diversas e com bastante propriedade.

Segundo Ludke e André (1986, p. 18): “o estudo qualitativo, é o que se desenvolve numa situação natural, é rico em dados descritivos, tem um plano aberto e flexível e focaliza a realidade de forma complexa e contextualizada". Por sua vez, a pesquisa quantitativa nos fornece subsídios para analisar os dados quantificáveis, buscando a confirmação por meio dos elementos organizados. Nesse sentido, Malhotra (2001, p.155), afirma que "a pesquisa qualitativa proporciona uma melhor visão e compreensão do contexto do problema, enquanto a pesquisa quantitativa procura quantificar os dados e aplica alguma forma da análise estatística".

Nesta parte, organizamos e analisamos os dados coletados em três blocos: matrículas, evasão e reprovação.

\subsection{MATRÍCULAS}

A seguir, os dados são referentes à matrícula dos alunos ayoreos ${ }^{\text {viii }}$, comparados aos dos estudantes brasileiros, residentes no município de Porto Murtinho, e brasileiros/paraguaios não indígenas, em 2017, separados em duas tabelas, sendo uma do ensino fundamental I ( $1^{\circ}$ ao $5^{\circ}$ ano) e outra do ensino fundamental II ( $6^{\circ}$ ao $9^{\circ}$ ano). $\mathrm{O}$ objetivo é identificar se os avanços das séries/anos levam à redução no número de matrículas.

\begin{tabular}{lccccccc}
\hline Anos & \multicolumn{2}{c}{ Brasileiros } & \multicolumn{2}{c}{ Paraguaios } & \multicolumn{2}{c}{ Ayoreos } & Total \\
& Número & $\%$ & Número & $\%$ & Número & $\%$ & \\
\hline $1^{\mathbf{o}}$ ano & 83 & 88,30 & 3 & 3,19 & 8 & 8,51 & 94 \\
$2^{\mathbf{o}}$ ano & 94 & 94 & 3 & 3 & 3 & 3 & 100 \\
$3^{\mathbf{o}}$ ano & 103 & 87,29 & 7 & 5,93 & 8 & 6,78 & 118 \\
$4^{\mathbf{o}}$ ano & 89 & 89,90 & 6 & 6,06 & 4 & 4,04 & 99 \\
$5^{\circ}$ ano & 60 & 92,31 & 2 & 3,08 & 3 & 4,62 & 65 \\
Total & 429 & 90,13 & 21 & 4,41 & 26 & 5,46 & 476 \\
\hline
\end{tabular}

Tabela 1 - Alunos matriculados no ensino fundamental I, em 2017

Fonte: Escola Municipal

Como podemos observar na tabela 1 , no ano de 2017, foram matriculados 476 alunos no $1^{\mathrm{o}}$ ao $5^{\circ}$ ano do ensino fundamental I, sendo que 429 educandos eram brasileiros, ou

DOI: $10.29327 / 214648.8 .31-1$ 
seja, pouco mais de $90 \%$ do total de matriculados; e 47, residentes no Paraguai, o que corresponde a quase 10\% do total de matriculados. Desses 47, temos 21 que moravam na cidade de Carmelo Peralta e 26, na comunidade indígena Ayoreo. Conforme a referida tabela, verificamos que existe uma demanda significativa de alunos que residem no país vizinho e que buscam o ensino fundamental brasileiro nos anos iniciais. Os resultados também mostram que esses educandos, que estão matriculados desde $o 1^{\circ}$ até o $5^{\circ}$ ano, à medida que vão avançando nas etapas de ensino, o número de ayoreos matriculados vai se reduzindo. Além disso, cabe ressaltar que eram 47 alunos que atravessavam o rio para estudar, quantidade significativa que demonstra a necessidade de um acompanhamento desse grupo.

\begin{tabular}{lccccccc}
\hline \multicolumn{1}{c}{ Anos } & \multicolumn{2}{c}{ Brasileiros } & \multicolumn{2}{c}{ Paraguaios } & \multicolumn{2}{c}{ Ayoreos } & Total \\
& Número & $\%$ & Número & $\%$ & Número & $\%$ & \\
\hline $6^{\mathbf{0}}$ ano & 99 & 92,52 & 7 & 6,54 & 1 & 0,93 & 107 \\
$7^{\mathbf{o}}$ ano & 89 & 93,68 & 6 & 6,31 & 0 & 0 & 95 \\
$8^{\circ}$ ano & 85 & 96,59 & 3 & 3,40 & 0 & 0 & 88 \\
$9^{\circ}$ ano & 70 & 93,33 & 5 & 6,66 & 0 & 0 & 75 \\
Total & 343 & 93,97 & 21 & 5,75 & 1 & 0,27 & 365 \\
\hline
\end{tabular}

Tabela 2 - Alunos matriculados no ensino fundamental II, em 2017

Fonte: Escola Municipal

No ano de 2017, o número total de alunos matriculados do $6^{\circ}$ ao $9^{\circ}$ ano do ensino fundamental II, conforme a tabela 2, correspondeu a 365 educandos, sendo que, desse total, 343 eram brasileiros e 22, residentes no Paraguai, o que corresponde a quase $6 \%$ do total de alunos matriculados. Desse grupo de 22 estudantes, 21 eram paraguaios e apenas um ayoreo. Como é possível observar, em comparação à tabela 1, o quantitativo de alunos paraguaios, na tabela 2 , se mantém. Por sua vez, o número de matrículas dos estudantes indígenas ayoreos demonstrou uma queda brusca: são 26 alunos ayoreos no ensino fundamental I e apenas um no ensino fundamental II.

Avaliamos que essa diferença pode ocorrer devido à falta de uma integração efetiva dos alunos, ausência de uma metodologia mais voltada para o contexto multilíngue e multicultural, bem como de materiais didáticos específicos, além da necessidade de o aluno trabalhar, conforme podemos observar no cotidiano da fronteira. Muitas crianças e jovens deixam de estudar para poderem ajudar seus pais financeiramente, em busca de melhores condições de vida. Na maioria das vezes, trata-se de trabalho braçal nas fazendas, próximas de sua residência. Outras ajudam seus familiares na pesca de peixes e iscas que servem de venda e subsistência das famílias. A causa da evasão e da reprovação, por motivos de trabalho, também foi apontado em outras pesquisas como nas de Auriglietti (2014), Fornari (2010), Silva Filho e Lima Araújo (2017), por exemplo.

\subsection{EVASÃO}

DOI: $10.29327 / 214648.8 .31-1$ 
Nesta parte, também apresentamos o quantitativo de alunos brasileiros, paraguaios e ayoreos evadidos, distribuído em duas tabelas: a do ensino fundamental I ( $1^{\circ}$ ao $5^{\circ}$ ano) e a do ensino fundamental II ( $6^{\circ}$ ao $9^{\circ}$ ano).

\begin{tabular}{cccccccc}
\hline Anos & $\begin{array}{c}\text { Brasileiros } \\
\text { No evadidos/ } \\
\text { No matriculados }\end{array}$ & $\%$ & $\begin{array}{c}\text { Paraguaios } \\
\text { No evadidos/ } \\
\text { No matriculados }\end{array}$ & $\begin{array}{c}\text { Ayoreos } \\
\text { No evadidos/ } \\
\text { No matriculados }\end{array}$ & $\%$ & Total \\
\hline $1^{\mathbf{o}}$ ano & $0 / 83$ & 0 & $0 / 3$ & 0 & $1 / 8$ & 12,5 & 1 \\
$2^{\mathrm{o}}$ ano & $0 / 94$ & 0 & $0 / 3$ & 0 & $2 / 3$ & 66,66 & 2 \\
$3^{\mathbf{o}}$ ano & $2 / 103$ & 1,94 & $0 / 7$ & 0 & $1 / 8$ & 12,5 & 3 \\
$4^{\mathbf{o}}$ ano & $0 / 89$ & 0 & $0 / 6$ & 0 & $0 / 4$ & 0 & 0 \\
$5^{\mathbf{o}}$ ano & $1 / 60$ & 1,66 & $0 / 2$ & 0 & $1 / 3$ & 33,33 & 2 \\
Total & $3 / 429$ & 0,69 & $0 / 21$ & 0 & $5 / 26$ & 19,23 & 8 \\
\hline
\end{tabular}

Tabela 3 - Alunos evadidos no ensino fundamental I, em 2017

Fonte: Escola Municipal

Na tabela 3, visualizamos a evasão dos alunos por meio dos dados obtidos a partir de registros da escola. No ano de 2017, no ensino fundamental I, o maior percentual de estudantes evadidos foi dos ayoreos, correspondendo a 19,23\%. Em contrapartida, a evasão dos outros dois grupos não alcançou 1\%. Esse resultado evidencia a importância da atenção para com a permanência dos ayoreos na escola.

\begin{tabular}{|c|c|c|c|c|c|c|c|}
\hline \multirow[t]{2}{*}{ Anos } & \multicolumn{2}{|c|}{ Brasileiros } & \multicolumn{2}{|c|}{ Paraguaios } & \multicolumn{2}{|c|}{ Ayoreos } & \multirow[t]{2}{*}{ Total } \\
\hline & $\begin{array}{c}\text { No evadidos/ } \\
\text { No matriculados }\end{array}$ & $\%$ & $\begin{array}{c}\text { No evadidos/ } \\
\text { No matriculados }\end{array}$ & $\%$ & $\begin{array}{c}\text { No evadidos/ } \\
\text { No matriculados }\end{array}$ & $\%$ & \\
\hline $6^{\circ}$ ano & $5 / 99$ & 5 & $0 / 7$ & 0 & $1 / 1$ & 100 & 6 \\
\hline $7^{\circ}$ ano & $5 / 89$ & 5,61 & $0 / 6$ & 0 & $0 / 0$ & 0 & 5 \\
\hline $8^{\circ}$ ano & $1 / 85$ & 1,17 & $0 / 3$ & 0 & $0 / 0$ & 0 & 1 \\
\hline $9^{\circ}$ ano & $1 / 70$ & 1,42 & $1 / 5$ & 20 & $0 / 0$ & 0 & 2 \\
\hline Total & $12 / 343$ & 3,5 & $1 / 21$ & 4,76 & $1 / 1$ & 100 & 14 \\
\hline
\end{tabular}

Tabela 4 - Alunos evadidos no ensino fundamental II, em 2017

Fonte: Escola Municipal

Proporcionalmente, na tabela 4, o maior índice de evasão indicado é o referente aos ayoreos. Há somente uma matrícula e o único aluno não conseguiu concluir o ano letivo, configurando $100 \%$ de evasão. Tanto a tabela 3 quanto a 4 demonstram que os maiores índices de evasão correspondem ao grupo indígena. Esse dado é altamente relevante para discutir a necessidade de ações que promovam a integração desse grupo na comunidade escolar, estratégias de acolhimento e de aprendizagem.

\subsection{REPROVAÇÃO}

DOI: $10.29327 / 214648.8 .31-1$ 
Nas tabelas seguintes, são apresentados os dados relativos a alunos brasileiros, paraguaios e ayoreos reprovados, também distribuídos em duas tabelas: a do ensino fundamental I ( $1^{\circ}$ ao $5^{\circ}$ ano) e a do ensino fundamental II ( $6^{\circ}$ ao $9^{\circ}$ ano).

\begin{tabular}{|c|c|c|c|c|c|c|c|}
\hline \multirow[t]{3}{*}{ Anos } & \multicolumn{2}{|l|}{ Brasileiros } & \multicolumn{2}{|l|}{ Paraguaios } & \multicolumn{2}{|l|}{ Ayoreos } & \multirow[t]{3}{*}{ Total } \\
\hline & No reprovados/ & $\%$ & No reprovados/ & $\%$ & No reprovados/ & $\%$ & \\
\hline & No matriculados & & No matriculados & & No matriculados & & \\
\hline $1^{\circ}$ ano & $4 / 83$ & 4,81 & $0 / 3$ & 0 & $3 / 8$ & 37,5 & 1 \\
\hline $2^{\circ}$ ano & $2 / 94$ & 2,12 & $0 / 3$ & 0 & $0 / 3$ & 0 & 2 \\
\hline $3^{\circ}$ ano & $25 / 103$ & 24,2 & $4 / 7$ & 57,1 & $4 / 8$ & 50 & 3 \\
\hline $4^{\circ}$ ano & $21 / 89$ & 23,5 & $1 / 6$ & 16,6 & $0 / 4$ & 0 & 0 \\
\hline $5^{\circ}$ ano & $6 / 60$ & 10 & $0 / 2$ & 0 & $0 / 3$ & 0 & 2 \\
\hline Total & $58 / 429$ & 13,5 & $5 / 21$ & 23,8 & $7 / 26$ & 26,9 & 8 \\
\hline
\end{tabular}

Tabela 5 - Alunos reprovados no ensino fundamental I, em 2017

Fonte: Escola Municipal

Nos dados expostos na tabela 5, é possível verificar que os educandos que apresentam maior percentual de reprovação são os ayoreos, constituindo $26,9 \%$ na proporção reprovados/matriculados. Entre os 26 ayoreos matriculados do $1^{\circ}$ ao $5^{\circ}$ ano, 7 estudantes reprovaram, o que corresponde a quase $1 / 4$ do grupo. Ainda conforme a tabela, é possível notar que os maiores índices de reprovações aconteceram no $1^{\circ}$ ano, que é o início da alfabetização, assim como da adaptação e integração escolar e, no $3^{\circ}$ ano, que deveria ser o ciclo final de alfabetização e letramento dos alunos. No caso dos ayoreos, no $1^{\circ}$ ano, há $37,5 \%$ de reprovação e, no $3^{\circ}$ ano, metade dos matriculados foram reprovados.

\begin{tabular}{lclccccc}
\hline Anos & $\begin{array}{l}\text { Brasileiros } \\
\text { No reprovados/ } \\
\text { No matriculados }\end{array}$ & $\%$ & $\begin{array}{l}\text { Paraguaios } \\
\text { No reprovados/ } \\
\text { No matriculados }\end{array}$ & \multicolumn{2}{c}{$\begin{array}{l}\text { Ayoreos } \\
\text { No reprovados/ } \\
\text { No matriculados }\end{array}$} & $\%$ & Total \\
\hline $6^{\mathbf{o}}$ ano & $18 / 99$ & 18,1 & $2 / 7$ & 28,5 & $0 / 1$ & 0 & $20 / 107$ \\
$7^{\mathbf{o}}$ ano & $16 / 89$ & 17,9 & $1 / 6$ & 16,6 & $0 / 0$ & 0 & $17 / 95$ \\
$8^{\mathbf{o}}$ ano & $19 / 85$ & 22,3 & $1 / 3$ & 33,3 & $0 / 0$ & 0 & $20 / 88$ \\
$9^{\mathbf{o}}$ ano & $15 / 70$ & 21,4 & $2 / 5$ & 40 & $0 / 0$ & 0 & $17 / 75$ \\
Total & $68 / 343$ & 19,8 & $6 / 21$ & 28,5 & $0 / 1$ & 0 & $75 / 365$ \\
\hline
\end{tabular}

Tabela 6 - Alunos reprovados no ensino fundamental II, em 2017 Fonte: Escola Municipal

Conforme a tabela 6, verificamos que temos apenas um aluno ayoreo matriculado somente no $6^{\circ}$ ano. Devido às dificuldades, reprovações e evasão, os dados demonstram que eles desaparecem nos anos finais do ensino fundamental II $\left(7^{\circ}, 8^{\circ}\right.$ e $9^{\circ}$ anos). Quando feito o comparativo de estudantes reprovados em relação aos matriculados, observamos que não há reprovação dos ayoreos, o que não quer dizer que o mesmo tenha sido aprovado. Conforme visualizamos na tabela 4 , o único matriculado no ensino fundamental não concluiu o ano letivo, entrando para a estatística dos evadidos.

DOI: $10.29327 / 214648.8 .31-1$ 
Além disso, notamos que o percentual de reprovados paraguaios é maior que o dos brasileiros. O alto índice de reprovação desses estudantes pode estar relacionado à necessidade trabalhar, às dificuldades de aprendizado e de comunicação em virtude de a língua utilizada na escola ser diferente da língua usada na comunidade, da falta de uma metodologia diferenciada para o contexto multicultural e multilíngue, por exemplo. Julgamos fundamental discutir as questões propostas por Souza e Senna (2016), no que diz respeito à necessidade de formação específica para professores que atuam em escolas de fronteira, além da importância de construir material didático específico que valorize a diversidade cultural e histórica, evitando preconceitos.

\section{CONSIDERAÇÕES FINAIS}

Vivemos em um país que apresenta diversidade linguística e cultural que vai muito além da comunicação. Essa pluralidade está refletida em vários aspectos: sociais, econômicos, educacionais, entre outros. Principalmente em regiões de fronteira, é possível vivenciar espaços multiculturais e multilíngues, mas que também retratam circunstâncias de conflitos alicerçados a questões de língua, linguagem, comunicação, diferenças culturais/étnicas e aprendizagem escolar. Nesse contexto, a presente pesquisa procurou mostrar, por meio dos levantamentos obtidos, os índices de matrícula, evasão e reprovação dos estudantes ayoreos, no período do ano de 2017, indicando algumas hipóteses para compreender essas ocorrências, com base em estudos de Fornari (2010), Silva Filho e Lima Araújo (2017) e Souza e Senna (2016), por exemplo. A investigação apontou que os estudantes que residem no país vizinho, o Paraguai, mas que possuem dupla cidadania, apresentam maior número de evasão e reprovação escolar, sobretudo os indígenas ayoreos.

Com base nas análises dos dados coletados, é possível verificar que há maior quantitativo de matrículas de alunos residentes no Paraguai nos anos iniciais do ensino fundamental. No decorrer das etapas de ensino, o número vai sendo reduzido, principalmente do grupo dos ayoreos, o que caracteriza a presença de dificuldades, sejam elas de caráter social, econômico, linguístico etc. Portanto, devido a vários fatores possíveis, entre os quais citamos com base em nossa observação local e na fundamentação teórica exposta, morar no Paraguai e estudar no Brasil, a língua utilizada na escola ser diferente da usada no ambiente familiar, a necessidade de ter que trabalhar, a falta de a escola desenvolver uma metodologia diferenciada para contextos multiculturais e multilíngues, a dificuldade na interação com os colegas, por exemplo, resultam em obstáculos para continuarem os estudos.

É importante salientar que, embora se fale em inclusão ou em acolhimento, no âmbito da educação nacional, muitas vezes, o tema se restringe a aspectos teóricos, leitura e

DOI: $10.29327 / 214648.8 .31-1$ 
discussões, e não necessariamente se desenvolve na prática. Se a comunicação é um importante elemento de aproximação e interação, torna-se altamente relevante que, em zonas fronteiriças, as escolas trabalhem com dois idiomas ou mais idiomas usados na região, evitando isolamento de alunos, a falta de compreensão e posicionamentos xenófobos. Obviamente, este trabalho não esgota as análises, ao contrário, instiga-nos a dar continuidade à investigação, uma vez constatada a problemática discutida. Julgamos importante aprofundar estudos sobre as motivações para a matrícula de ayoreos em escolas brasileiras e as causas que levam aos altos índices de evasão e reprovação das crianças indígenas.

\section{REFERÊNCIAS}

AURIGLIETTI, R. C. R. Evasão e abandono escolar: causas, consequências e alternativas - o combate à evasão escolar sob a perspectiva dos alunos. In: Cadernos PDE. Vol. 1. Curitiba: Governo do Estado do Paraná, Secretaria de Educação, 2014, p. $1-21$.

BARROS, A. L. de E. C. de. Fronteira(s) Paraguai/Brasil: Narrativas sobre (de) colonialidade, culturas, línguas e identidades. Campinas, SP: Pontes Editores, 2017.

BARTOLOMÉ, M. A. El encuentro de la gente y los insensatos: La sedentarización de los cazadores Ayoreo en el Paraguay.México/DF: Instituto Indigenista Interamericano/ CEADUC, 2000.

BHABHA, H. K. O local da cultura. Belo Horizonte: Editora UFMG, 1998.

BRASIL, Ministério da Educação e do Desporto. Lei de Diretrizes e Bases. Brasília: Congresso Nacional, dezembro, 1996. 2001.

Plano Nacional de Educação, Lei n ${ }^{\circ} 10.172$ de 9 de janeiro de 2001. Brasília,

FIORIN, J. L. Prefácio. In: MOITA LOPES, L. P. (Orgs.). O português no século XXI: cenário geopolítico e sociolinguístico. São Paulo: Parábola. 2013, p. 13-17.

FORNARI, L. T. Reflexões acerca da reprovação e evasão escolar e os determinantes do capital. REP: Revista Espaço Pedagógico, v. 17, n. 1, Passo Fundo, p. 112-124, jan./jun. 2010.

FRANCO, A. L. Ética, ciência e cultura jurídica: IV Congresso Nacional da FEPODI: [Recurso eletrônico on-line]. Organização FEPODI/ CONPEDI/ANPG/PUCSP/UNINOVE; coordenadores: Livia Gaigher Bosio Campello, Mariana Ribeiro Santiago - São Paulo: FEPODI, 2015.

DOI: $10.29327 / 214648.8 .31-1$ 
GIL, A. C. Como elaborar projetos de pesquisa. 4 ed. São Paulo: Atlas, 2002.

GRÜNEWALD, L. Um grupo e(m) transformação: “o xamanismo ayoreo”. Espaço Ameríndio, Porto Alegre, v. 11, n. 1, p. 11-42, jan./jun. 2017.

INICIATIVA AMOTOCODIE. Los Ayoreo en el norte del Chaco paraguayo: volume $8, \mathrm{n}^{\mathrm{o}} 2$, dezembro de 2016. Informe 2014-2015. Iniciativa Amotocodie.

LÜDKE, M.; ANDRÉ, M. E. D. A. Pesquisa em educação: Abordagens qualitativas. São Paulo: EPU, 1986.

MACHADO, L. O. Limites, Fronteira, Redes. In: STROHAECKER, Tânia Marques. et.al (Org). Fronteiras e Espaço Global. Porto Alegre: AGB - Seção Porto Alegre, 1998, p. 41-49.

MALHOTRA, N. Pesquisa de marketing. 3. ed. Porto Alegre: Bookman, 2001.

OLIVEIRA, J. P. de (Org.). A viagem da volta: Etnicidade, política e reelaboração cultural no nordeste indígena. 2 ed. Rio de Janeiro: Contra Capa, 2004.

PATTO, M. H. S. A produção do fracasso escolar: histórias de submissão e rebeldia. 2. ed. São Paulo: Casa do Psicólogo, 1999.

PARAGUAY. Dirección General de Estadística, Encuentros y Censos Pueblos indígenas en el Paraguay. Resultados preliminares. III - Censo Nacional de Población y Viviendas para Pueblos Indígenas: Fabián Marti, DGEEC, 2012.

PIMENTA, J. Povos indígenas, fronteiras amazônicas e soberania nacional. Algumas reflexões a partir dos Ashaninka do Acre. Trabalho apresentado na mesa redonda: Grupos indígenas na Amazônia. SBPC, Manaus, 2009.

PORTO MURTINHO, Lei Municipal No 1569, de 24 de junho de 2015. Aprova o Plano Municipal de Educação.

SHIRASU, M. R.; ARRAES, R. de A. (2016). Determinantes da Evasão e Repetência Escolar. In: Anais do XLIII Encontro Nacional de Economia da ANPEC Associação Nacional dos Centros de Pós-graduação em Economia. Disponível em: $<$ https://www.anpec.org.br/encontro/2015/submissao/files_I/i12-85f3c

3774c3d65741cb278e01e61db39.pdf>. Acesso em: 1 set. 2019.

SILVA, Z. R. Práticas pedagógicas interculturais na tríplice fronteira Brasil, Colômbia e Peru: um estudo na Escola Estadual Marechal Rondon. Dissertação (Mestrado). Universidade Federal de Santa Catarina, Florianópolis, SC, 2011, 198 p.

DOI: $10.29327 / 214648.8 .31-1$ 
SILVA FILHO, R. B.; LIMA ARAÚJO, R. M. de. Evasão e abandono escolar na educação básica no Brasil: fatores, causas e possíveis consequências. Educação por escrito, Porto Alegre, v. 8, n. 1, p. 35-48, jan.-jun. 2017.

SOUZA, J. M. P.; SENNA, L. A. G. Desafios para inclusão de imigrantes em escolas de regiões fronteiriças. Textos e debates, Boa Vista, n. 30, p. 55-68, jul./dez., 2016.

STURZA, E. R. Línguas de fronteira: o desconhecido território das práticas linguísticas nas fronteiras. Revista Ciência e Cultura, Vol. 57, nº 2, abril-junho. São Paulo, 2005.

THIESSE, A. La création des identités nationales: Europe XVIII e XX siècle. Paris: Editions du Seuil, 1999.

\footnotetext{
i Muitas famílias que residem no Paraguai buscam auxílio no município brasileiro. As mulheres paraguaias que dão à luz a seus filhos, em Porto Murtinho, por exemplo, garantem o direito de usufruírem dos benefícios oferecidos no âmbito da saúde e da educação a seus descendentes. Diante dessa realidade, a busca das famílias pelo acesso ao ensino dessas crianças cresce gradativamente, evidenciando a carência de projetos e ações em prol do referido grupo.

ii Lei Municipal n 1616 , de 8 de maio de 2017.

iii Trata-se de um nome fictício.

iv No estudo desenvolvido por Souza e Senna (2016), a parcela a que se referem são os imigrantes, não falantes de português. A pesquisa considerou a presença de alunos falantes de inglês, nas escolas de Bonfim, no estado de Roraima, e de falantes de espanhol, nas de Foz do Iguaçu, no estado do Paraná. ${ }^{v}$ Todas as citações em língua estrangeira são traduções livres nossas. No original: "para poder seguir siendo hay que dejar de ser mucho de lo que se era".

${ }^{v i}$ No original: El pueblo Ayoreo es conocido desde los primeros tiempos de la conquista del Chaco. En el siglo XVI son nombrados diversos grupos que luego, en el siguiente siglo, se asociarán a la etnia de los Zamuco; a quienes posteriormente (en la tercera década del siglo XX) se los identifica como Ayoreo.

vii No original: Van dejando señales de su existencia diferenciada, como testimonios anónimos de una lucha silenciosa contra la hegemonía impuesta por las naciones modernas. Herencias dispersas de un pueblo que fue sometido y reducido, caminan diseminados por los bosques chaqueños, configurando constelaciones irreconciliables con la fiebre de capital que domina al colonizador, al neoamericano y, poco a poco, a los descendientes de quienes fueron originales de la región.

viii Todos os alunos matriculados, na referida escola, têm nacionalidade brasileira. Neste trabalho, denominaremos brasileiros os que têm o português como língua materna; paraguaios são os falantes de espanhol e guarani e que residem na colônia Carmelo Peralta; ayoreos os que fazem parte da comunidade Punta, também em Carmelo Peralta, mas que têm o zamuco como língua materna.
}

*Graduada em Letras Português-Espanhol pela Universidade Federal de Mato Grosso do Sul (UFMS), Faculdade de Artes, Letras e Comunicação (FAALC), Professora efetiva na Rede Municipal de Educação de Porto Murtinho. E-mail: lucidiabalbuena@gmail.com.

**Doutora em Educação pela Universidade de São Paulo (USP), Professora do curso de graduação em Letras Português-Espanhol e do Programa de Pós-Graduação em Estudos de Linguagens da FAALC/UFMS. E-mail: daniela.ead.ufms@gmail.com.

DOI: $10.29327 / 214648.8 .31-1$ 